\title{
Inclusion of shared sanitation in urban sanitation coverage? Evidence from Ghana and Uganda
}

\author{
ADRIEN MAZEAU, INNOCENT K. TUMWEBAZE, \\ CHRISTOPH LÜTHI and KEVIN SANSOM
}

This paper discusses the notions of 'improved' and 'unimproved' sanitation in the context of developing countries in urbanizing Africa and considers the role that shared facilities can play in this equation. It analyses current definitions and classifications used by the United Nations Joint Monitoring Programme (JMP) to monitor access to shared sanitation and summarizes the recent discourse on JMP's limitations. Empirical evidence from two case studies in sub-Saharan Africa (SSA) - Kampala, Uganda and Ashaiman, Ghana - is presented, showing the widespread use and limitations of the shared toilet facilities in these two cities. The empirical evidence shows that quite different types of shared sanitation facilities emerge in different cities, each influenced by the urbanization patterns, local politics and sociocultural considerations. Improving the quality of shared facilities involves the consideration of the applicability of the different types of facilities within the category 'shared sanitation', together with an improved understanding of the users' determinants of acceptability, such as access and cleanliness. The paper concludes with a discussion of potential indicators for shared sanitation post-2015 global monitoring, as a means of integrating shared sanitation into the overall sanitation access figures.

Keywords: accessibility, indicators, shared toilets, user acceptability

THE INTERNATIONAL DEBATE ON WHAT constitutes 'adequate' or 'acceptable' sanitation has gained prominence in light of post-2015 global sanitation monitoring of the Millennium Development Goal (MDG Target 7c). The development of post-2015 targets and indicators for safe drinking water and basic sanitation is now under way with international core working groups mainly led by the Joint Monitoring Programme (JMP), while the sanitation group was led by the World Bank Water \& Sanitation Program (WSP). This working group is currently developing a new list of possible indicators, identifying consistent data sources and methods of analysis to measure progress for the next 25 year period between 2015 and 2040 (C. Zurbrügg, member of JMP Post 2015 working group on sanitation, pers. comm., 2012).

Adrien Mazeau (a.mazeau@lboro.ac.uk) is a PhD student at the Water, Engineering and Development Centre (WEDC), Loughborough University, UK. Innocent K. Tumwebaze is a PhD student of psychology at the University of Zurich. Dr Christoph Lüthi is a Senior Scientist in the Department for Water and Sanitation in Developing Countries at the Swiss Federal Institute of Aquatic Science and Technology (Eawag). Kevin Sansom is a lecturer in the Water, Engineering and Development Centre (WEDC) at the School of Civil and Building Engineering, Loughborough University.

(C) Practical Action Publishing, 2013, www.practicalactionpublishing.org http://dx.doi.org/10.3362/1756-3488.2013.034, ISSN: 0262-8104 (print) 1756-3488 (online) 
One of the controversial issues is the adequacy and acceptability of shared sanitation facilities - one of the most ubiquitous sanitation solutions in urban areas of the developing world - rising from 13 per cent in 1990 to 17 per cent in 2010 (WHO and UNICEF, 2012a). Currently, the Joint Monitoring Programme (JMP) does not include shared facilities in the 'improved' facilities category (WHO and UNICEF, 2012a). While the JMP does acknowledge the importance of such toilets compared with no facilities at all, it considers the lack of cleanliness and the lack of accessibility of shared facilities to be unacceptable (WHO and UNICEF, 2012a). In 2012 the JMP Sanitation Working Group made very specific recommendations for including shared toilets in the post-2015 targets, including a definition of 'adequate sanitation' that includes shared toilets under certain circumstances (for instance, shared by fewer than five families, and by people who know each other) (WHO and UNICEF, 2012b) but further research is required - this is considered in the Discussion and conclusions section.

Several sector experts have argued that in more densely populated urban areas, shared sanitation is the most technically and financially viable solution that exists (Schaub-Jones et al., 2006; Mara and Alabaster, 2008). In addition, UN-Habitat also considers a shared toilet to be 'improved' if an acceptable number of people use it - without defining the maximum number of users (UN-Habitat, 2006). This paper aims to examine some of the limitations of the current JMP classification of shared vs. individual facilities. It discusses some of the key parameters to consider beyond the number of users per (shared) toilet cubicle by providing empirical evidence from recent field research in urban Ghana and urban Uganda. The empirical data from Uganda and Ghana is then used to discuss potential indicators for shared sanitation for post-2015 global monitoring, as a means of integrating shared sanitation into the overall sanitation access figures.

\section{The need for redefining shared toilets}

Shared sanitation is a common phenomenon in urban areas of low-income countries, but they are often 'not incorporated in conscious planning' (Schaub-Jones et al., 2006: 4). The work of the JMP has been questioned regarding the exclusion of shared facilities from the 'improved' facilities category (van der Hoek et al., 2010). The JMP acknowledges the importance of such toilets compared with no facilities at all but does not categorize it as 'improved' sanitation: 'recent JMP estimates may have underestimated the proportion of the population that uses an "improved" sanitation facility by excluding all households classified as using a shared or public sanitation facility' (UNICEF and WHO, 2010: 2).

'Sometimes shared toilets work and sometimes they do not' (Rakodi, 2005). While some scholars recognize that shared toilets do offer some appreciable services to a part of the population, they state that this form of sanitation typically does not always meet the hygiene requirements of users, may pose a risk to personal security (WSUP, 2011), and may also be difficult for the elderly and disabled to access (Cairncross and Valdamis, 2006). Shared facilities are also often associated with greater health 
risks (Allen et al., 2008). However, empirical data from existing studies are unable to prove that typical individual toilets provide significantly greater health benefits than typical shared facilities.

Today, the JMP recognizes that many urban households only have access to sanitation by sharing facilities. Therefore the JMP states the need for further research focusing on the acceptability of shared facilities and has added the number of users sharing toilets in 2005 to its data collection. Some authors call for 'an evidencebased maximum number of households using one "improved" sanitation facility" (Van der Hoek et al., 2010: 48). Finding agreement on which form of shared toilet should be considered 'improved' by the different monitoring platforms presents several difficulties:

- Scholars and implementers often do not present a clear framework of the different types of shared toilets.

- The concept of sanitation has several dimensions, most of which are context specific. These dimensions include toilet management and the legal and institutional framework as well as sociocultural norms and user behaviour.

- Similarly the notion of a household is also context specific. The JMP uses the household as the main unit of measurement, but the definition of a household is understood differently depending on culture (Rakodi, 1995). This paper uses the household definition suggested by IWA Sanitation 21 . The household is used to describe the personal sphere within which households (families, individuals, small units, etc.) take investment and behavioural decisions together. In a household, individuals share the same dwelling and cooking arrangements. A household in Ashaiman will typically use one or two room(s) of a larger housing unit.

- The notion of improved sanitation and satisfaction can be seen through a range of varying perspectives, going from cleanliness to access or safety. Who sets the assessment criteria (Black and Fawcett, 2008)?

If there is a re-categorization of acceptable shared facilities as 'improved' urban sanitation, it would have a significant effect on future reported levels of sustainable access to improved sanitation facilities beyond 2015 in many countries which have a significant proportion of 'acceptable' shared sanitation facilities.

\section{Adding rungs to the sanitation ladder}

The sanitation ladder used by the JMP to monitor sanitation progress consists of four categories: open defecation, 'unimproved', shared, and 'improved' sanitation facilities. The fraction of the population using shared sanitation has significantly increased during recent years, reaching 15 per cent of the urban population in developing countries in 2010. This figure was much larger (31 per cent) and is increasing amongst the sub-Saharan urban population, see Table 1.

Such levels of usage suggest that careful consideration be given to how shared facilities can be incorporated in future global sanitation access assessments. The data presented in Table 1 does not differentiate between a public toilet used by 
Table 1 Percentage of urban population sharing toilet facilities

\begin{tabular}{lccc}
\hline & $\begin{array}{c}1990 \\
(\%)\end{array}$ & $\begin{array}{c}2000 \\
(\%)\end{array}$ & $\begin{array}{c}2010 \\
(\%)\end{array}$ \\
\hline Urban Ghana & 44 & 59 & 73 \\
Urban Uganda & 48 & 49 & 50 \\
Urban sub-Saharan Africa (SSA) & 28 & 29 & 31 \\
\hline
\end{tabular}

Source: WHO and UNICEF, 2012a

Table 2 Range of shared toilets

\begin{tabular}{ll}
\hline Category & Definition \\
\hline $\begin{array}{l}\text { Household toilet } \\
\begin{array}{l}\text { Landlord or } \\
\text { neighbour shared }\end{array}\end{array}$ & $\begin{array}{l}\text { Toilet serving a single household } \\
\text { Toilet shared by several defined households known to each other and } \\
\text { used following an informal agreement often managed by a landlord. } \\
\text { Different payment options exist but the use of the toilet is often } \\
\text { included in the rent }\end{array}$ \\
$\begin{array}{l}\text { Community toilet } \\
\text { Toilet shared by a group of identified households in a community and } \\
\text { often managed by a community-based organization. Payments are } \\
\text { often done on a pay-per-use basis }\end{array}$ \\
$\begin{array}{l}\text { Toilet often located in the city centre, and near markets, but also in } \\
\text { residential areas. Public facilities are open to anybody and can be } \\
\text { privately or publicly owned and managed. Payments are often done } \\
\text { on a pay-per-use basis }\end{array}$ \\
\hline
\end{tabular}

Source: adapted from WSUP, 2011

hundreds of people and a shared facility used by two families. There is therefore a need to further disaggregate the so-called 'shared sanitation category', see Table 2 .

Implementers need to consider the full range of shared toilet options, recognizing their potential for being a transitional stage. Public toilets are the lowest rung of the sanitation ladder due to the problematic management issues, and shared facilities at household level will be higher up (Schaub-Jones et al., 2006). Such a ladder will allow a better understanding and integration of such facilities and of their users in future sanitation upgrading programmes.

\section{Methods and presentation of cases studies}

This paper analyses results from two on-going $\mathrm{PhD}$ research studies in urban areas of Ghana and Uganda. The two research projects, supported by extended field work, specifically evaluate the role played by shared toilets in low income urban areas.

The two studies were built with different methodologies, as they were developed independently. They, however, consider a large number of common issues with a clear emphasis on access to toilet facilities. The notion of access to infrastructure and health services is widely used, although there are different interpretations of its definition. To allow the analysis of the two sets of data, the paper uses four dimensions of access, namely: availability, accessibility, affordability, and 
Table 3 Dimensions of acceptability used in this paper

\begin{tabular}{|c|c|c|}
\hline \multirow[t]{4}{*}{ Access to toilet } & Availability & $\begin{array}{l}\text { Number of users per toilet seat } \\
\text { Nature of toilet providers }\end{array}$ \\
\hline & Accessibility & $\begin{array}{l}\text { Physical accessibility } \\
\text { Social accessibility }\end{array}$ \\
\hline & Affordability & $\begin{array}{l}\text { Forms of payment } \\
\text { Price for toilet use }\end{array}$ \\
\hline & Acceptability & $\begin{array}{l}\text { Cleanliness } \\
\text { Other determinants (safety, privacy, etc.) }\end{array}$ \\
\hline
\end{tabular}

acceptability (Penchansky and Thomas, 1981) with some key components of each dimension, see Table 3.

\section{Ashaiman case study}

Ashaiman is a part of the greater Accra area. Ashaiman has one of the fastest population growth rates in Ghana, growing from 20,000 in 1970 to more than 220,000 in 2010. The expansion of Ashaiman was poorly planned and led to several infrastructure challenges including a high percentage of people using shared sanitation facilities (Mazeau et al., 2012). In 2011, the municipality of Ashaiman counted 25 municipal-owned public toilets and over 150 owned by entrepreneurs.

The field work done in 2011 entailed a survey of 432 housing units in four low-income areas of Ashaiman, including 2,912 households. Sanitation surveys were done for all shared toilets used by the residents. Fifteen participatory groups of residents did a mapping of their daily sanitation usages and scored the type of facilities they used. Semi-structured interviews with 30 households and 10 sanitation providers offered a clearer picture of the evolution of the sanitation facilities in Ashaiman.

\section{Kampala case study}

According to the Uganda Bureau of Standards' 2011 mid-year population estimation, Kampala has a total population of $1,659,600$. Over 60 per cent of the population in Kampala was living in slums (UBOS, 2005). Slums are settlement areas within urban towns or cities largely characterized by informal and unplanned settlement patterns and mostly lacking access to adequate sanitation facilities (UN-Habitat, 2006). Most of the population in Uganda relies on on-site sanitation (Tumwebaze et al., 2012). Only 6 per cent of the urban areas in Uganda have sewerage coverage.

The field survey conducted in 2010 in Kampala assessed the sanitation situation from 50 randomly selected slums. The slums were sampled across the five divisions that make up Kampala district. Two-stage random sampling was applied. The first stage was selecting the 50 zones (slums) using Stata, from a compiled list of 188 slums, and the second stage was systematic sampling at the household level (Tumwebaze et al., 2012). Within each sampled slum, 30 households were randomly selected. 
To obtain a wide coverage proportional to the zone, we used systematic sampling, interviewing a respondent on every third house block. Only one household was interviewed on this block. If the first household respondent did not consent to participate in the study, the interviewer moved on to the next household. A total of 1,500 household respondents participated in this survey using a semi-structured questionnaire.

\section{Findings}

Many sector professionals call for a re-categorization of shared toilets as 'improved' sanitation, and determining which parameters characterize the different dimensions of sharing is an ongoing debate. The number of households sharing a toilet cubicle has been put forward as a key factor in determining if a shared toilet is 'improved' or not. Figure 1 is based on this suggestion using an arbitrary threshold of five households per toilet cubicle, to show the extent of households sharing a cubicle in both locations. This paper uses the term 'cubicle'; however, the terms stances, seats, rooms, and drop holes are also found in the literature. In Uganda, the term cubicle

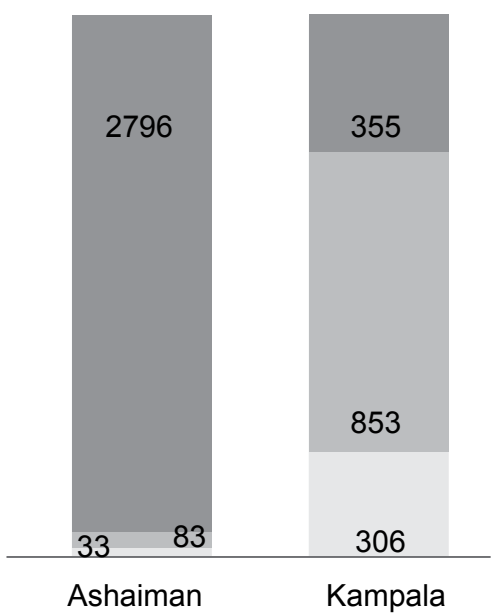

1 household

2-5 households

$>5$ households

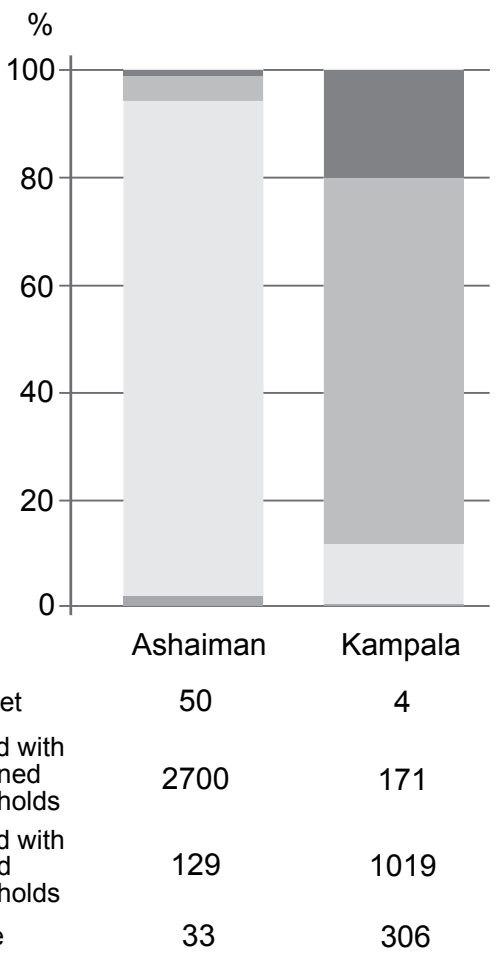

Figure 2 Type of sanitation arrangement used in
Ashaiman and Kampala

Figure 2 Type of sanitation arrangement used in
Ashaiman and Kampala Source: field research data 2010 and 2011

\begin{tabular}{|ccc|}
\hline $\begin{array}{l}\text { No toilet } \\
\text { Shared with } \\
\text { undefined }\end{array}$ & 50 & 4 \\
$\begin{array}{l}\text { households } \\
\begin{array}{l}\text { Shared with } \\
\text { defined } \\
\text { households }\end{array}\end{array}$ & 2700 & 171 \\
$\begin{array}{l}\text { Private } \\
\text { Prive }\end{array}$ & 33 & 1019 \\
\hline
\end{tabular}

Figure 1 Comparison of number of households sharing a toilet cubicle Source: field research data 2010 and 2011 
is referred to as a stance while in Ghana a toilet block is described as, for example, a 10-seat toilet block.

This cut-off figure of five households was suggested by the JMP Technical Task Force as a possible threshold (UNICEF and WHO, 2010). The assumption is that management of a facility used by five or fewer households is likely to be easier as the households know each other through, for instance, co-housing. However, the same document reckons that there is no empirical evidence to suggest that five households are a better guarantee of safe use and management of toilet facility than four or six households.

In Kampala, most households share toilets with $<5$ households, whereas in Ashaiman, most of the toilet cubicles are shared by a much larger number of households than the suggested threshold. The size of shared toilets, their number of users, and their prevalence vary significantly from one African city to another. This questions the applicability of such a threshold in capturing a substantial proportion of people using adequate shared facilities.

As an alternative critieria for assessing improved shared sanitation, this paper considers two main categories of toilets:

- A toilet shared with defined households. The access to a toilet is restricted to a certain number of households who generally know one another. It can be households living in the same compound, in houses managed by the same landlords or part of a common extended family.

- A toilet shared with undefined households. This will typically apply to households using public toilets where it is not possible to know all toilet users and where the number and identity of users varies daily. These toilets are often pay-to-use types.

\section{Type of sanitation facilities used}

In Kampala, 85 per cent of the sampled households and over 95 per cent of the households in Ashaiman share the toilets with at least one other household. The type of sanitation arrangements are summarized in Figure 2, highlighting the low number of households with access to individual sanitation facilities in Ashaiman and Kampala.

Most of the households in Ashaiman rely on facilities located outside their housing unit that are used by an undefined and fluctuating group of households. In contrast, 68 per cent of Kampala's slum dwellers rely on a toilet used by a limited number of defined households who know each other. The differences in these shared sanitation arrangements relate to the urban history and characteristics of the two cities.

In the surveyed areas of Ashaiman, the number of functional toilets inside the house units or compounds has decreased due to the banning of bucket latrines, bad management of the facilities or flooding of the pit. This has led to development of public toilet blocks located outside the house premises that vary in size from 3 to 30 cubicles and are managed by private entrepreneurs.

Even with the increasing population growth in Kampala's slums, the dwellers tend to be accommodated by the existing shared toilets, albeit with growing numbers of users per toilet cubicle. 
Availability. Table 4 shows how the number of households per toilet cubicle is related to the type of toilet facility. In the case of toilets shared by undefined households, the numbers of households sharing a cubicle is around 30 in Ashaiman and 60 in Kampala (the mean household size in Ashaiman is 3.5 and 4.5 in Kampala). These values may underestimate the reality as these toilets are also used by dwellers of neighbouring slums or people passing through.

Table 4 Comparative number of households per cubicle for households sharing facilities

\begin{tabular}{lcccc}
\hline & $\begin{array}{c}\text { Access to toilet private or shared } \\
\text { with defined households }\end{array}$ & \multicolumn{2}{c}{$\begin{array}{c}\text { Access to toilet shared with } \\
\text { undefined households }\end{array}$} \\
\hline Location & Ashaiman & Kampala & Ashaiman & Kampala \\
Households & 162 & 739 & 2,750 & 671 \\
$\begin{array}{l}\text { Estimated households per } \\
\text { stance or seat (mean) }\end{array}$ & 2 & 4.5 & 30 & 61 \\
\hline
\end{tabular}

Note: the mean number of households per cubicle in Kampala is calculated based on the 1,500 household surveys. In Ashaiman, the number of users of each category was divided by the number of available cubicles.

Source: field research data 2010 and 2011

The toilets used by a defined group of households have a lower number of users per toilet cubicle in both locations. The number and the distribution of toilet facilities within an urban area impact on the queuing time, which is likely to increase if there is a shortage of seats or cubicles. During peak hours in the morning, users queue up to 15 minutes for toilets located outside housing premises in Ashaiman. In Kampala, 46 per cent of shared toilet users with defined households reported that they never queue to use their toilet, against 11 per cent who never queue when using larger facilities with undefined users.

Toilet providers. The nature of individuals or institutions that invest in sanitation and build or provide toilets varies from one urban context to another, depending on the different local conditions. The large majority of the toilets shared by defined households are built and managed by private landlords, in both Ashaiman and Kampala. The larger community or public toilets shared by undefined households are built and managed by different stakeholders:

- In Kampala, 55 per cent of these public-access facilities are provided by the municipality, followed by NGOs.

- In Ashaiman, most of these facilities are built and managed by private entrepreneurs. Other toilet blocks are owned by the municipality, and very few are built and managed by NGOs.

Physical accessibility. In both cities, the toilets open to all (e.g. used by non-defined users) are scattered within the neighbourhood and users may have to walk several minutes to access them. However, they may offer a suitable solution for the disabled and elderly as they may include better design: with smaller steps, access ramps, and 
light within the cubicles. This can be observed in the recently built sanitation blocks in Ashaiman. In contrast, toilets built in compounds for the use of a limited number of households are very close to their users, but they are often structures without appropriate steps and lighting.

Social accessibility. The social accessibility is seen through two main lenses: gender and children. In Kampala, the majority of women and men shared the same toilet, though both men and women expressed the desire to have separate toilet cubicles. Most of the larger toilets shared by undefined households in Ashaiman offer separate cubicles for men and women. When a toilet with two cubicles is located in a compound house, one cubicle will often be used by the landlord family and the second cubicle used by the tenants. Interestingly, for the households sharing toilets with undefined neighbours it was observed that half of the sampled married participants use different toilet facilities from their partner. Overall, women in the Ashaiman sample give more importance than men to the privacy and safety of the facilities they used. Likewise, female respondents in Kampala attached more importance to using toilets with privacy and safety than their male counterparts.

Potties used by a large percentage of children under five are often disposed of in the shared toilets close to the housing unit. In the case of toilets shared with undefined users, these facilities often require a payment to dispose of the potty's contents in both cities. For children, no special price reductions are observed in Kampala for public toilets, and a 50 per cent price reduction is offered in only two toilet blocks in the Ashaiman case. It is therefore likely that faeces from children living in a house with no access to toilets are disposed of in the open, in gutters or in plastic bags thrown in the garbage.

Affordability. Another important component of access to toilets is the price and the payment mode, particularly for households who only have access to pay-per-use facilities. The toilets shared by defined households are often built by the landlords, sometimes with support from CBOs, as in the case of Kampala. Users usually pay for access to such toilets as part of the house rent in Kampala, although 38 per cent of tenants are also asked to cost-share for the cost of desludging. In Ashaiman, tenants and landlords often divide the cost of desludging by the number of household members. For the Ashaiman families sharing with undefined neighbours, it is reported during household interviews that people may go for open defecation or to the cheapest and most dilapidated facilities during times of economic difficulties.

In the case of pay-per-use toilets, the price per visit in Kampala ranges between 100 and 500 Uganda shillings (US\$0.04-0.20). This price is however dependent on the geographical location of the facility, with those in the centre of the city being the most expensive. In Ashaiman the price per use ranges between 10 pesewas and 40 pesewas (US\$0.05-20). The most expensive blocks are located in the business area (markets and taxi stations) and managed by private entrepreneurs, which are not affordable for many poorer users. The less expensive facilities are generally older and of poor quality, and are owned by the municipality and managed by individuals based on some leasing contracts. 
Acceptability - cleanliness. During scoring exercises held in Ashaiman, the toilets that were rated better in term of cleanliness were the larger toilet blocks which were managed by private entrepreneurs. When it came to cleanliness, the size of the toilet was of less importance than the management arrangements.

In Kampala, 17 per cent of the shared toilets with defined households were reported to be dirty by their users, but the figure was much higher ( 41 per cent) for public facilities. The level of cleanliness reduced with the increasing number of households sharing a toilet. From our data it is not quite clear if it is the number of users, the relation between them or the combination of both that is the key factor.

The empirical findings of the two case studies underline the importance of cleanliness as a key factor of acceptability. However, privacy and safety are some of the other determinants which should be examined further.

\section{Discussion and conclusions}

In Kampala we find that most households share toilets with between two and five other 'defined' households, which are often managed by landlords, whereas in Ashaiman the vast majority of people share with more than five other 'undefined' households. There are also considerable differences between the two cities in terms of who develops and manages the shared facilities, as well as the level of sharing of the facilities by men, women, and children.

Where individual household sanitation is not possible or foreseeable in the short and medium term due to lack of space or funds, shared sanitation represents the most accessible alternative to open defecation or flying toilets; even if it is only a transitional arrangement. Shared toilets are not included in the JMP overall urban sanitation access figures despite the high proportion of urban dwellers relying on them. Risks to health, difficulty of access for certain population groups, and affordability may justify this exclusion in many cases. Current international thinking that shared facilities cannot be classified as 'improved' sanitation as stipulated by the JMP needs to be reconsidered. The shared sanitation category includes a range of models that are not captured by the traditional sanitation ladder, such as neighbour shared latrines, community toilets, and public toilets. The relative merits of these different types of shared toilets should be considered more widely.

Given the high levels of usage of shared sanitation facilities in many countries, careful consideration should be given to how shared facilities can be incorporated in future global sanitation access assessments. What emerges from studies of urban shared sanitation is the multi-various factors that influence whether shared sanitation can be considered adequate or improved in any given situation. These many factors can be difficult to measure in household surveys for future JMP assessments. Perhaps a summary indicator could be used such as 'user acceptability' that can represent the many factors that influence the adequacy of the shared sanitation facilities? It is also clear that smaller scale shared sanitation facilities that are closer to users present fewer management and access problems than larger communal toilet blocks. Similar remarks were made during an Indian case study 
Table 5 Potential indicators for integrating shared sanitation into overall sanitation access figures post-2015

\begin{tabular}{|c|c|c|}
\hline Potential indicators & Potential benefits & Potential challenges \\
\hline $\begin{array}{l}\text { 1. Percentage of households } \\
\text { who regularly use shared } \\
\text { toilets which have been } \\
\text { deemed acceptable by a toilet } \\
\text { survey }\end{array}$ & $\begin{array}{l}\text { Cleanliness and condition of } \\
\text { toilets are key determinants of } \\
\text { safe use } \\
\text { Most accurate indicator } \\
\text { for determining if shared } \\
\text { sanitation is improved or safe }\end{array}$ & $\begin{array}{l}\text { The cost of additional shared } \\
\text { toilet condition/cleanliness } \\
\text { surveys } \\
\text { Such surveys are not } \\
\text { generally done for individual } \\
\text { households }\end{array}$ \\
\hline $\begin{array}{l}\text { 2. Percentage of households } \\
\text { who regularly use toilets } \\
\text { that are shared by up to five } \\
\text { households. The notion of } \\
\text { 'regular use' is important } \\
\text { because evidence suggests } \\
\text { that a significant percentage } \\
\text { of users of shared toilet } \\
\text { facilities may resort to open } \\
\text { defecation under certain } \\
\text { circumstances, such as high } \\
\text { entry charges to communal } \\
\text { latrines }\end{array}$ & $\begin{array}{l}\text { Relatively easy to assess as } \\
\text { part of national household } \\
\text { surveys } \\
\text { The indicator is already part of } \\
\text { the MICS and DHS surveys }\end{array}$ & $\begin{array}{l}\text { Only limited evidence to } \\
\text { suggest that an arbitrary } \\
\text { threshold (of, say, five) for } \\
\text { the number of households } \\
\text { using a shared toilet is more } \\
\text { valid than, say, six or eight } \\
\text { households sharing a toilet }\end{array}$ \\
\hline $\begin{array}{l}\text { 3. Percentage of households } \\
\text { who regularly use toilets that } \\
\text { are shared only by defined } \\
\text { households whom they know }\end{array}$ & $\begin{array}{l}\text { Similar benefits to option } 2 \text {, } \\
\text { although it has the advantage } \\
\text { of not using an arbitrary } \\
\text { number of households } \\
\text { sharing } \\
\text { This indicator is already part } \\
\text { of the MICS survey }\end{array}$ & $\begin{array}{l}\text { Would not include larger } \\
\text { acceptable quality toilet } \\
\text { blocks (over } 100 \text { users for } \\
\text { instance), where there is } \\
\text { sharing with undefined } \\
\text { households }\end{array}$ \\
\hline $\begin{array}{l}\text { 4. Percentage of households } \\
\text { who regularly use shared } \\
\text { toilets and consider that the } \\
\text { cleanliness and condition } \\
\text { of the toilet they use is } \\
\text { acceptable }\end{array}$ & $\begin{array}{l}\text { Based on user perspective of } \\
\text { acceptability } \\
\text { Potentially more accurate } \\
\text { compared with indicators } 2 \\
\text { and } 3 \text {, because it does not } \\
\text { exclude users of particular } \\
\text { types of facilities that may be } \\
\text { of good quality }\end{array}$ & $\begin{array}{l}\text { The notion of 'user } \\
\text { acceptability' may seem } \\
\text { subjective to some who are } \\
\text { concerned with the provision } \\
\text { of safe or hygienic toilet } \\
\text { facilities. It would therefore } \\
\text { need to be tested }\end{array}$ \\
\hline
\end{tabular}

(Biran et al., 2011). Bearing these aspects in mind, potential indicators for shared sanitation for post-2015 global monitoring are proposed in Table 5, as a means of integrating shared sanitation into the overall sanitation access figures, followed by discussion of the merits of each indicator.

\section{Option 1: Assessment of condition and cleanliness by survey of shared toilets}

This indicator focuses on cleanliness which appears to be a key determining factor for the use of shared sanitation facilities. Biran et al. (2011) found from exit interviews that cleanliness, lighting, lack of smell, and the availability of soap and 
water are valued by latrine users. A list of toilet survey parameters would need to be agreed: for example, no excrement, liquids, and vermin on the toilet slab. But this indicator would require a survey of the shared facilities in addition to the traditional household surveys used by the JMP. This would entail considerable survey costs and challenges in coordinating such toilet surveys with the relevant national household surveys.

\section{Option 2: Assessment by number of households who use a shared toilet}

In the literature, a causal link is often made between the hygienic status of a shared toilet and its number of users (Cotton et al., 1995), arguing that management and cleaning of facilities is easier with fewer users. This option could encompass neighbours sharing toilets, where users have to travel shorter distances compared with larger communal or public latrines. By having such a clear threshold of five households, it is relatively easy to measure as part of household surveys. In Kampala, Günther et al. (2012) found that if a sanitation facility is shared by five or more households, this leads to a large fraction of unhygienic toilets. Further evidence is needed to show if an arbitrary threshold (of, say, five) for the number of households using a shared toilet is any more valid than, say, six or eight households sharing a toilet.

However in Ashaiman, 96 per cent of households share with more than five households. The smaller facilities shared by a lower number of households were less clean than some of the larger, privately managed facilities. Larger shared facilities in the form of community sanitation blocks in India, for example, show that the cost recovery and maintenance of such facilities will depend on the number of users and smaller blocks with lower usage levels are not always a viable or sustainable solution (Triche and McIntosh, 2009). So this indicator definition is likely to underestimate the number of households who are using good quality, larger, shared toilet facilities, while potentially overestimating the percentage of smaller toilet blocks of adequate quality.

\section{Option 3: Assessment of shared sanitation that is only used by defined households whom they know}

This option has similar benefits to option 2 in terms of having a lower risk of unhygienic facilities with a large number of users. The results from Kampala and Ashaiman indicate that community or public toilets have around 13 to 15 times as many users per stance or cubicle compared with toilets that are used by defined users or neighbour-shared facilities. This indicator has the advantage over option 2 in not setting an arbitrary number of households who are sharing. However, this indicator option would not include larger, acceptable quality toilet blocks (over 100 users for instance), where there is sharing with undefined households. The potential limitations of this option are similar to option 2 . 


\section{Option 4: Assessment by user perceptions of acceptability of shared toilets}

This indicator can potentially lead to the most accurate overall figures for access to 'improved' sanitation among users of shared sanitation facilities, compared with other options. This is because it does not exclude users of particular types of facilities that may be of a good quality. 'User acceptability' is similar to the concept of user or customer satisfaction, which is widely used in the commercial and public sectors. But the notion of 'user acceptability' may seem subjective to some who are concerned with the provision of safe or hygienic toilet facilities.

In the Kampala study (Günther et al., 2012), interviewers recorded 27 per cent of 1,500 sanitation facilities being unclean, which was confirmed by the picturecoding method of inspection, which yielded the same result. This would suggest that consumer perceptions of acceptable toilet cleanliness can be reasonably accurate, although respondents were less accurate compared with independent observers in assessing their own toilets. In Ashaiman, the toilets poorly rated by the respondents are also poorly rated by the researchers' toilet survey. Whether the assessment of 'user acceptability' on issues such as cleanliness and condition can represent the main concerns related to shared sanitation as improved access will need to be tested further.

\section{Concluding comments}

The evidence suggests that what might emerge as a suitable indicator in one city, may not be as appropriate in another location. The potential indicators set out in Table 5 could be reviewed together with any other potential shared sanitation indicators with a view to pilot testing the validity of these indicators, for integrating shared sanitation into overall sanitation access figures, post-2015. Pilot testing could involve using these indicators in household surveys within a number of defined areas to assess the extent to which each indicator under- or overestimates the percentage of households who are using shared sanitation that can be regarded as adequate or 'improved' in accordance with the JMP definition. While the JMP Sanitation Working Group has proposed the maximum of 30 persons or five families (whichever number is lower) to define shared sanitation as 'adequate', this has been questioned at the Second Consultation on Post-2015 Monitoring at The Hague in December 2012. Further research to strengthen the evidence base had been commissioned (WHO and UNICEF, 2012b: 34). The alternative indicators and the associated analysis presented in this paper can contribute to such research. Further research on the use of shared sanitation by women and children is also recommended.

Clearly, providing recommendations on what should be considered improved shared sanitation and how to classify this is a difficult undertaking, given the varied findings of this and other studies. However, the following factors are seen as important in encouraging better quality sanitation facilities closer to where people live: 1) the lower the number of defined households sharing a facility, the better; 2 ) careful consideration of the mechanisms agreed to use, operate, and maintain the facility; and 3) the importance of cleanliness as a key factor of acceptability - the 
dirtier and more unusable a toilet becomes, the more likely it is that users will resort to unsafe practices such as open defecation.

\section{References}

Allen, A., Hofmann, P. and Griffiths, H. (2008) 'Moving down the ladder: governance and sanitation that works for the urban poor', IRC Symposium: Sanitation for the urban poor. Partnerships and Governance, Delft, The Netherlands: IRC.

Biran, A., Jenkins, M.W., Dabrase, P. and Bhagwat, I. (2011) 'Patterns and determinants of communal latrine usage in urban poverty pockets in Bhopal, India', Tropical Medicine and International Health 16 (7): 854-62 <http://dx.doi.org/10.1111/j.1365-3156.2011.02764.X>.

Black, M. and Fawcett, B. (2008) The Last Taboo: Opening the Door on the Global Sanitation Crisis, London: Earthscan Publications Ltd.

Cairncross, S. and Valdamis, V. (2006) 'Water supply, sanitation, and hygiene promotion', in D. Jamison, J. Breman, A. Measham, M. Claeson, D. Evans, P. Jha, A. Mils and P. Musgove (eds), Disease Control Priorities in Developing Countries, 2nd edn, New York: Oxford University Press.

Cotton, A., Franceys, R., Pickford, J. and Saywell, D. (1995) On-plot Sanitation in Low-income Urban Communities: A Review of Literature, Loughborough, UK: Water, Engineering and Development Centre (WEDC).

Günther, I., Horst, A., Lüthi, C., Mosler, H., Niwagaba, B. and Tumwebaze, K. (2012) When is Shared Sanitation Improved? The Correlation between Number of Users and Toilet Hygiene. Research for Policy 2 [online], Switzerland: ETH Zurich <www.nadel.ethz.ch/publikationen/policy_ brief_shared_sanitation_improved_2_2012.pdf> [accessed 2013].

Mara, D. and Alabaster, G. (2008) 'A new paradigm for low-cost urban water supplies and sanitation in developing countries', Water Policy 10 (2): 119-29 <http://dx.doi.org/10.2166/ wp.2008.034>.

Mazeau, A., Scott, R. and Tuffuor, B. (2012) 'Sanitation, a neglected essential service in the unregulated urban expansion of Ashaiman', Sustainable Future Conference, Kampala, Uganda.

Penchansky, R. and Thomas, J. (1981) 'The concept of access: definition and relationship to consumer satisfaction', Medical Care 19 (2): 127-40.

Rakodi, C. (1995) 'Poverty lines or household strategies? A review of conceptual issues in the study of urban poverty', Habitat International 19: 407-26 <http://dx.doi.org/ 10.1016/0197-3975(95)00037-G>.

Rakodi, C. (2005) 'The urban challenge in Africa', in M. Keiner, M. Koll-Schretzenmayr and W. Schid (eds), Managing Urban Futures: Sustainability and Urban Growth in Developing Countries. Hampshire, UK: Ashgate Publishing.

Schaub-Jones, D., Eales, K. and Tyers, L. (2006) Sanitation Partnerships: Harnessing their Potential for Urban On-site Sanitation, BPD sanitation series, London: Building Partnership for Development in Water and Sanitation.

Triche, T. and McIntosh, A. (2009) Improving Water Supply and Sanitation Services for the Urban Poor in India. Water and Sanitation Program Guidance Notes, New Dehli, India: Water and Sanitation Program South Asia.

Tumwebaze, I., Orach, C., Niwagaba, C., Lüthi, C. and Mosler, H. (2012) 'Sanitation facilities in Kampala slums, Uganda: users' satisfaction and determinant factors', International Journal of Environmental Health Research 23 (3): 191-204 <http://dx.doi.org/10.1080/09603123.2012.713095>. 
UBOS (2005) 2002 Uganda Population and Housing Census: Main report, Kampala, Uganda: Uganda Bureau Of Statistics.

UN-HABITAT (2006) State of the World's Cities, Report 2006/2007, Nairobi, Kenya: United Nations Human Settlements Programme.

UNICEF and WHO (2010) JMP Technical Task Force, Meeting on Sanitation and Methods for Estimating Progress, New York: UNICEF.

van der Hoek, W., Evans, B., Bjerre, J., Calopietro, J. and Konradsen, F. (2010) 'Measuring progress in sanitation', in DANIDA (ed.), Reaching the MDG Target for Sanitation in Africa - A Call for Realism, pp. 42-50, Denmark: Ministry of Foreign Affairs.

WHO and UNICEF (2012a) Progress on Sanitation and Drinking-water: 2012 Update. World Health Organization and United Nations Children's Fund Joint Monitoring Programme for Water Supply and Sanitation, New York: UNICEF; Geneva: WHO.

WHO and UNICEF (2012b) Report of the Second Consultation on Post-2015 Monitoring of DrinkingWater, Sanitation and Hygiene, The Hague, 3-5 December 2012. World Health Organization and United Nations Children's Fund, Joint Monitoring Programme for Water Supply and Sanitation, New York: UNICEF; Geneva: WHO.

WSUP (Water \& Sanitation for the Urban Poor) (2011) When are Communal or Public Toilets an Appropriate Option? Topic brief, London: WSUP. 